Original article

\title{
Laboratory-based surveillance of Shigella spp. from human clinical cases in Colombia, 1997-2018
}

\author{
Edna Catering Rodríguez, Adriana Marcela Bautista, Lucy Angeline Montaño, María
} Victoria Ovalle, Francia Patricia Correa

Grupo de Microbiología, Dirección de Redes en Salud Pública, Instituto Nacional de Salud, Bogotá, D.C., Colombia

Introduction: Shigellosis is endemic in low-and middle-income countries, causing approximately 125 million episodes of diarrhea and leading to approximately 160.000 deaths annually one-third of which is associated with children.

Objective: To describe the characteristics and antimicrobial resistance profiles of Shigella species recovered in Colombia from 1997 to 2018.

Materials and methods: We received isolates from laboratories in 29 Colombian departments. We serotyped with specific antiserum and determined antimicrobial resistance and minimal inhibitory concentrations for ten antibiotics with Kirby-Bauer tests following the Clinical and Laboratory Standards Institute recommendations.

Results: We analyzed 5,251 isolates of Shigella spp., most of them obtained from stools (96.4\%); 2,511 (47.8\%) were from children under five years of age. The two most common species were S. sonnei (55.1\%) and S. flexneri (41.7\%). The highest resistance rate was that of tetracycline $(88.1 \%)$ followed by trimethoprim-sulfamethoxazole $(79.3 \%)$ and ampicillin $(65.5 \%) ; 50.8 \%$ of isolates were resistant to chloramphenicol, $43.6 \%$ to amoxicillin/clavulanic acid, and less than $1 \%$ to cefotaxime, ceftazidime, gentamicin, and ciprofloxacin. In S. sonnei, the most common resistance profile corresponded to trimethoprim-sulfamethoxazole (92\%) whereas in S. flexneri the most common antibiotic profiles were multidrug resistance.

Conclusions. In Colombia, children under five years are affected by all Shigella species. These findings should guide funders and public health officials to make evidencebased decisions for protection and prevention measures. The antimicrobial resistance characteristics found in this study underline the importance of combating the dissemination of the most frequently isolated species, S. sonnei and S. flexneri.

Keywords: Dysentery, bacillary; public health surveillance; drug resistance, microbial; ampicillin; cephalosporins; fluoroquinolones; trimethoprim, sulfamethoxazole drug combination; chloramphenicol.

Accepted: $08 / 09 / 2020$

Published: 09/09/2020

Citation:

Rodríguez EC, Bautista AM, Montaño LA, Ovalle MV, Correa FP. Laboratory-based surveillance of Shigella spp. from human clinical cases in Colombia, 19972018. Biomédica. 2021;41:65-78.

https://doi.org/10.7705/biomedica.5113

\section{Corresponding author:}

Edna Catering Rodríguez, Grupo de Microbiología, Dirección de Redes en Salud Pública, Instituto Nacional de Salud, Avenida Calle $26 \mathrm{~N}^{\circ}$ 51-20 CAN, Bogotá, D.C., Colombia Teléfono: (51) 2207700 , extensión 1421 erodriguezc@ins.gov.co

\section{Author contributions:}

Edna Catering Rodríguez: manuscript conception, design, and writing

All authors participated in the data analysis and interpretation, the critical review of important intellectual content, and the approval of the final version, and they assume full responsibility for all aspects of the manuscript.

\section{Funding:}

Laboratory Surveillance on Shigella spp. by the Instituto Nacional de Salud microbiology laboratory has received support from Colciencias through the project "Fortalecimiento de la capacidad diagnóstica de investigación y de vigilancia de enfermedades transmisibles emergentes y reemergentes en Colombia".

\section{Conflicts of interest:}

The authors declare no conflicts of interest.

\section{Vigilancia por el laboratorio de Shigella spp. aislada de casos clínicos humanos en} Colombia, 1997-2018

Introducción. La shigelosis es endémica en los países de ingresos bajos y medios y ocasiona aproximadamente 125 millones de episodios de diarrea y 160.000 muertes al año, un tercio de los cuales se presenta en niños.

Objetivo. Describir las características y los perfiles de resistencia antimicrobiana en aislamientos de Shigella spp. recuperados en Colombia entre 1997 y 2018.

Materiales y métodos. Los aislamientos provenían de laboratorios en 29 departamentos de Colombia. La serotipificación se hizo con antisueros específicos de Shigella spp. y, la determinación de los perfiles de resistencia y la concentración inhibitoria mínima de diez antibióticos, por Kirby-Bauer.

Resultados. Se estudiaron 5.251 aislamientos de Shigella spp. obtenidos de materia fecal (96,4\%); el 47,8 \% de ellos correspondía a niños menores de cinco años. Las especies más frecuentes fueron S. sonnei $(55,1 \%)$ y S. flexneri $(41,7 \%)$. Se presentó resistencia a tetraciclina $(88,1 \%)$, trimetoprim-sulfametoxasol $(79,3 \%)$, ampicilina $(65,5 \%)$, cloranfenicol $(50,8 \%)$ y amoxicilina-acido clavulánico $(43,6 \%)$. La resistencia no superó el $1 \%$ contra cefotaxime, ceftazidima, gentamicina y ciprofloxacina. Para S. sonnei, el perfil de resistencia más frecuente correspondió a trimetoprim-sulfametoxasol, en contraste con S. flexneri, cuyos perfiles fueron todos multirresistentes.

Conclusiones. Los niños menores de cinco años se vieron afectados por todas las especies de Shigella spp., aspecto que los legisladores en salud pública deben considerar a la hora de tomar decisiones en torno a las medidas de prevención y protección frente a esta enfermedad. Las características de resistencia antimicrobiana de los aislamientos de Shigella spp. en Colombia ponen de manifiesto la importancia de combatir la diseminación de las dos especies más frecuentes en casos clínicos, S. sonnei y S. flexneri.

Palabras clave: disentería bacilar; vigilancia en salud pública; farmacorresistencia microbiana; ampicilina; cefalosporinas; fluoroquinolonas; combinación trimetoprim y sulfametoxazol; cloranfenicol. 
Diarrhea is a major global health issue causing 1.3 million deaths each year 500.000 of which occur in children less than five years of age (1). Shigellosis is endemic in most low- and middle-income countries and is the most important cause of bloody diarrhea worldwide (2). Recent estimates attribute to Shigella spp. approximately 125 million diarrhea episodes annually leading to approximately 160,000 deaths one-third of which are associated with young children $(1,3)$. The Global Enteric Multicenter Study revealed that Shigella spp. was the most prevalent causative agent in children aged 2 to 5 years who experienced diarrhea and suggested that the induced burden may be twice as high as previously estimated (4).

Shigella genus is divided into the following four species and into multiple serotypes dependent on O-antigen and biochemical differences: Shigella dysenteriae (serogroup A, 15 serotypes), Shigella flexneri (serogroup B, 19 serotypes), Shigella boydii (serogroup C, 20 serotypes), and Shigella sonnei (serogroup D, 1 serotype) (5). The pathogen spreads by direct contact with an infected person or by ingesting contaminated food or water. The infective dose can be as low as 10 microbes; its global importance arises from its wide distribution and water quality concerns that make it an important risk for public health (6). Shigella sonnei and S. boydii usually cause relatively mild illness with watery or bloody diarrhea while $S$. flexneri is the chief cause of endemic shigellosis in low- and middle-income countries (7).

Many observations have concluded that Shigella species are geographically stratified based on the level of economic development in each country. Shigella flexneri is the primary infectious species in low- and middleincome countries and $S$. sonnei rates increase with economic development. Shigella boydii is usually restricted to Bangladesh and South-East Asia rarely occurring outside these regions while $S$. dysenteriae type 1 (Sd1) outbreaks occur sporadically (8). Emerging multidrug-resistant Shigella isolates have exacerbated the public health impact of shigellosis leading to increased morbidity, mortality, and treatment costs $(2,9)$.

Given that Shigella is a major contributor to the global diarrhea burden, vaccination can be an effective strategy to prevent the disease. However, there are at least 50 recognized Shigella serotypes and their distribution differs among geographical regions hindering vaccine development (10).

Public health significant microorganisms in Colombia include Shigella spp. and Salmonella spp. These species are part of the surveillance of acute diarrheal diseases by public health laboratories and the Laboratorio de Microbiolog ía at the Instituto Nacional de Salud. Given the need to better understand the behavior of Shigella species at a national level, we report here the age of the population affected, the temporal and geographical characteristics of the isolates, and the antimicrobial resistance profiles of Shigella species recovered in the country from 1997 to 2018.

\section{Materials and methods}

Strains recovered from patients were collected in hospitals or public health laboratories and then sent to the Laboratorio de Microbiología at the Instituto Nacional de Salud to confirm their biochemical identification following the standardized procedures and to serotype them using commercial polyclonal and monoclonal typing antisera (Eurobium) in the framework of the acute diarrheal disease surveillance program (11). 
Antimicrobial resistance was determined using the Kirby-Bauer test against tetracycline $(30 \mu \mathrm{g})$, chloramphenicol $(30 \mu \mathrm{g})$, nalidixic acid $(30 \mu \mathrm{g})$, amoxicillin/clavulanic acid $(10 \mu \mathrm{g})$, and ciprofloxacin $(5 \mu \mathrm{g})$. Additionally, we obtained the minimal inhibitory concentrations (MIC) for ampicillin (8-16 $\mu \mathrm{g} /$ $\mathrm{ml})$, cefotaxime $(2-32 \mu \mathrm{g} / \mathrm{ml})$, ceftazidime $(1-16 \mu \mathrm{g} / \mathrm{ml})$, ciprofloxacin $(1-2$ $\mu \mathrm{g} / \mathrm{ml})$, gentamicin $(4-86 \mu \mathrm{g} / \mathrm{ml})$, and trimethoprim-sulfamethoxazole $(2 / 38$ $\mu \mathrm{g} / \mathrm{ml}$ ) with the Microscan® (Siemens) automated system following the recommendations of the Clinical and Laboratory Standards Institute yearly updated (12). Statistical significance ( $p$ value) was calculated with Epilnfo 7.

\section{Results}

We studied 5,251 isolates of Shigella spp. recovered in 29 Colombian departments. Bogotá, the country's capital city, sent the highest number of isolates $(n=3,257,62 \%)$. Another five states recovered more than one hundred isolates each: Antioquia $(n=814 ; 15 \%)$; Valle $(n=205 ; 3.9 \%)$; Norte de Santander ( $n=187 ; 3.6 \%)$; Nariño $(n=157 ; 3 \%)$, and Boyacá $(n=146 ; 2.8 \%)$. The additional 485 isolates were recovered from the other 23 departments.

The majority of isolates were obtained mainly from stools (96.4\%; $5,063 / 5,251)$ of patients whose ages ranged from newborns to 92 years. The children under one year of age contributed 452 isolates $(8.6 \%)$, and the patients between 2 and 5 years contributed 2,059 isolates (39.2\%); 1,498 $(28.5 \%)$ isolates were recovered from 6 to 14-year-old patients while 904 isolates $(17.2 \%)$ were recovered from those over 15 years (Table 1 ).

Two species were predominant representing together $96 \%$ of the strains: $2,896(55.1 \%)$ isolates were S. sonnei and 2,191 (41.7\%) were S. flexneri. Other species included S. boydii and S. dysenteriae with 103 and 14 isolates each. Some of the isolates had some of the typical characteristics of Shigella but it was not possible to identify them at the species level and, therefore, they were labeled as non-serotypeable Shigella. Non-serotypeable Shigella accounted for approximately 47 isolates, none of which were agglutinated with any antisera of the established Shigella serovars.

During the first three years of surveillance (1997-1999), S. flexneri was the dominant species decreasing after 2002 when S. sonnei became the most dominant and continued to be for 15 years, until 2016, when it became again the second most common strain (figure 1).

The highest resistance level was found for tetracycline (88.1\%) followed by trimethoprim-sulfamethoxazole (79.3\%), and ampicillin (65.5\%); 50.8\% of isolates were resistant to chloramphenicol and $43.6 \%$ to amoxicillin/ clavulanic acid. Less than $1 \%$ of the isolates were resistant to cephalosporins (cefotaxime and ceftazidime), gentamicin, and ciprofloxacin (table 2).

Table 1. Age and sample distribution

\begin{tabular}{lrrrrrr}
\hline \multicolumn{7}{c}{ Age in years } \\
\hline Sample type & \multicolumn{1}{c}{ 1 } & $\mathbf{2 - 5}$ & $\mathbf{6 - 1 4}$ & $\mathbf{> 1 5}$ & ND & Total \\
\hline Stool & 435 & 2,012 & 1,469 & 834 & 313 & 5,063 \\
NC & 6 & 24 & 15 & 18 & 18 & 81 \\
Blood & 8 & 10 & 4 & 36 & 6 & 64 \\
Urine & 2 & 11 & 4 & 13 & & 30 \\
Other & 1 & 2 & 6 & 3 & 1 & 13 \\
\hline Total & 452 & 2,059 & 1,498 & 904 & 338 & 5,251 \\
\hline
\end{tabular}

NC: Information not collected 


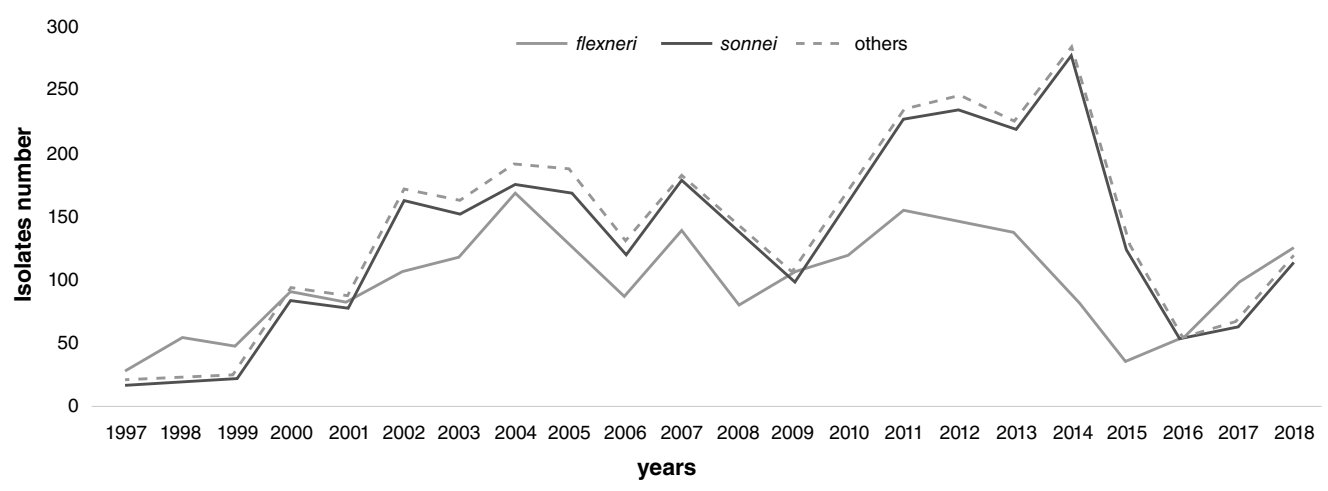

Figure 1. Distribution of Shigella spp. isolates in Colombia from 1997 to 2018 . S. flexneri (grey), S. sonnei (black), and other species (dashed line). This information was based on the annual Shigella surveillance system in Colombia.

Table 2. Antimicrobial resistant isolates distribution in different Shigella species

\begin{tabular}{lcccccllllll}
\hline Shigella & \multicolumn{10}{c}{ Antibiotics } \\
\cline { 2 - 10 } species & AMC & TE & C & NA & CAZ & CTX & AMP & SXT & CIP & GM \\
\hline boydii & 12.3 & 83.5 & 10.7 & 3.13 & 2.47 & 0.97 & 76.7 & 51.5 & 0 & 1.06 \\
dysenteriae & 0 & 41.7 & 7.14 & 11.1 & 0 & 0 & 28.6 & 42.9 & 0 & 0 \\
flexneri & 60.7 & 94.3 & 80.8 & 2.34 & 0.22 & 0.37 & 83 & 67.8 & 0.41 & 0.27 \\
Shigella spp. & 12.5 & 63.8 & 27.7 & 9.76 & 0 & 0 & 61.4 & 65.9 & 2.17 & 0 \\
sonnei & 32.8 & 83.9 & 29.4 & 7.15 & 0.4 & 0.43 & 52 & 89.6 & 0.49 & 0.37 \\
\hline Total & 43.6 & 88.1 & 50.8 & 5.13 & 0.36 & 0.41 & 65.5 & 79.3 & 0.46 & 0.34 \\
\hline
\end{tabular}

AMC: Amoxicillin/clavulanic acid; TE: Tetracycline; C: Chloramphenicol; NA: Nalidixic acid; CAZ: Ceftazidime; CTX: Cefotaxime; AMP: Ampicillin; SXT: Trimethoprim-sulfamethoxasole; CIP: Ciprofloxacin; GM: Gentamicin

\section{Geographical distribution, age, and antimicrobial resistance of species}

\section{Shigella sonnei}

Geographical distribution: S. sonnei represented more than half of the Colombian Shigella spp. isolates evaluated $(2,896,54.7 \%) ; 66 \%(1,975 / 2,896)$ of the isolates under study were recovered in Bogotá: 58 isolates detected in 2001 and 101 in 2002; 16\% of isolates were recovered in Antioquia while the remaining $17.8 \%$ were from the other 25 departments where the recovery increased between 2011 and 2014 as the highest number of isolates for this species came from those states in the last few years (figure 2).

There were 23 outbreaks in nine different departments (Antioquia, Bogotá, Boyacá, Cundinamarca, Nariño, Norte de Santander, Santander, Sucre, and Valle) with 80 related isolates. The outbreak that grouped most cases (12) occurred in Nariño in 2008. The isolates recovered in the other outbreaks registered there varied.

Age: Almost half of the isolates $(48 \%, 1390 / 2896)$ were recovered from children under 6 years of age. In the 6 to 14-year age group, S. sonnei was the most frequently recovered (32.6\% of isolates; $943 / 2896)$ (table 3 ).

Antimicrobial resistance: S. sonnei showed the highest resistance to trimethoprim-sulfamethoxazole $(89.6 \% ; 2,530 / 2,825)$ and to tetracycline (more than $80 \% ; 2,278 / 2,714)$. Resistance levels for nalidixic acid, chloramphenicol, amoxicillin/clavulanic acid, and ampicillin were 7\% (184/2,574), 29.4\% (803/2,733), 32.8\% (785/2,391), and 52\% (1469/2827), respectively (table 2); 14 isolates were resistant to ciprofloxacin, 12 to cefotaxime, 10 to ceftazidime, and 7 to gentamicin. 


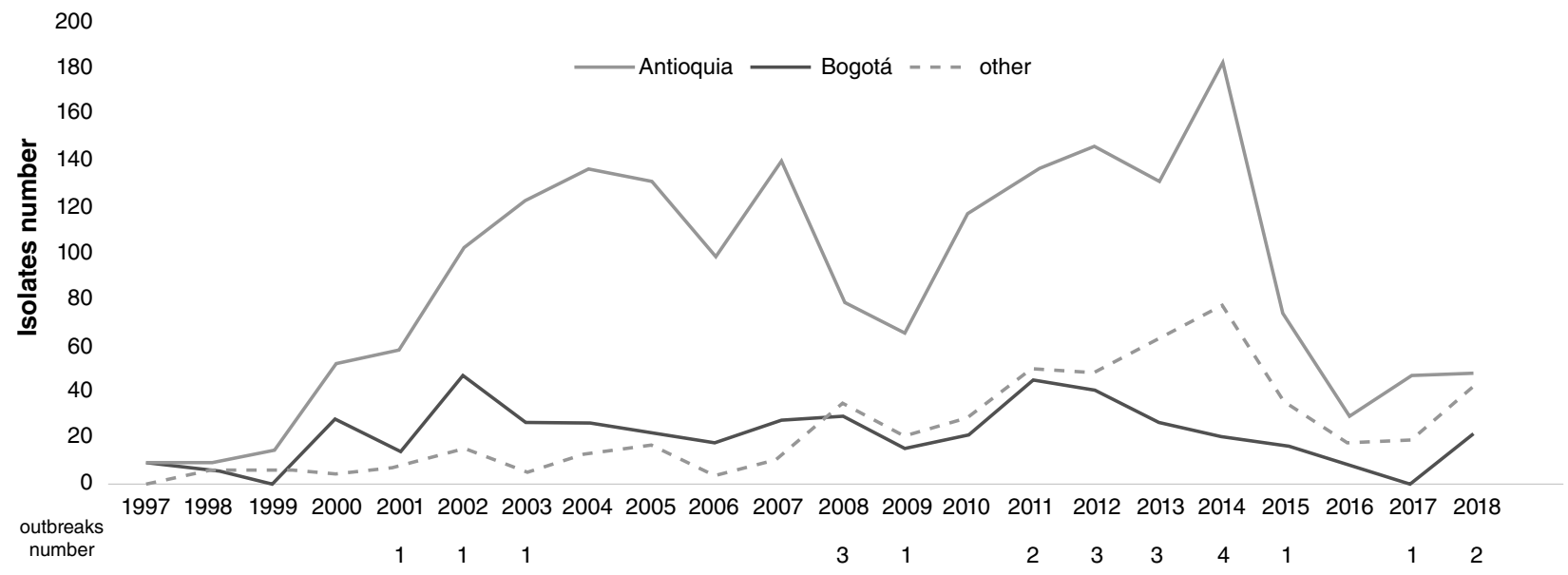

Figure 2. Comparison of the number and distribution of Shigella sonnei isolates in Antioquia (black), Bogotá (grey), and other regions (dashed line) in Colombia from 1997 to 2018

Table 3. Age range and Shigella species distribution

\begin{tabular}{lcrcrrr}
\hline \multicolumn{7}{c}{ Shigella species } \\
\hline Age in years & boydii & dysenteriae & flexneri & Shigella spp. & sonnei & Total \\
\hline$<1$ & 6.8 & 0.0 & 11.2 & 9.9 & 6.7 & 8.6 \\
2 to 5 & 30.1 & 28.6 & 37.2 & 34.1 & 41.3 & 39.3 \\
6 to 14 & 34.0 & 7.1 & 23.5 & 15.4 & 32.6 & 28.5 \\
$>15$ & 22.3 & 57.1 & 22.4 & 30.8 & 12.5 & 17.2 \\
NC & 6.8 & 7.1 & 5.7 & 9.9 & 7.0 & 6.5 \\
\hline
\end{tabular}

NC: information not collected

\section{Shigella flexneri}

A total of 321/2,191 isolates (14.65\%) were detected in Antioquia with increases in 2000, 2006, and 2012. Another 627 (28.6\%) isolates were recovered in 25 departments representing an increase as of 2016. Eleven outbreaks of $S$. flexneri were notified (figure 3 ) with 37 related isolates in five departments (Amazonas, Bogotá, Cundinamarca, Meta, and Nariño). The most important outbreak occurred in Cundinamarca in 2001 when 14 isolates were related to food consumed in a school (Figure 3).

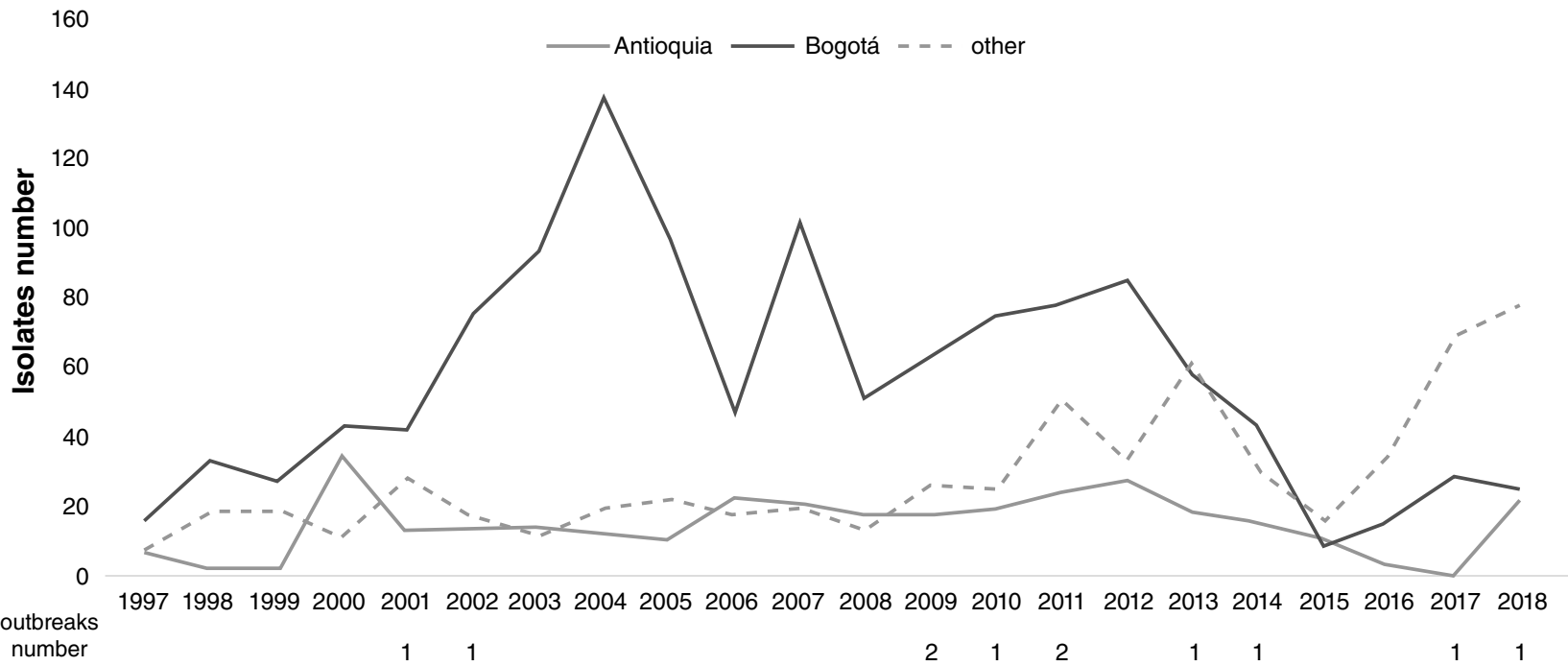

Figure 3. Comparison of the number and distribution of Shigella flexneri isolates in Antioquia (grey), Bogotá (black), and others regions (dashed line) in Colombia from 1997 to 2018 
Age: The number of $S$. flexneri isolates by age groups was similar. However, almost half of the isolates $(48.5 \%)$ were recovered in under six-yearold children (table 3).

Antimicrobial resistance: S. flexneri highest resistance rates were to tetracycline (94.3\% of isolates), ampicillin (83\%), chloramphenicol $(80.8 \%)$, and trimethoprim-sulfamethoxazole (67.8\%) (table 2). Less than 10 isolates were resistant to ciprofloxacin, cefotaxime, ceftazidime, and gentamicin.

\section{Other species}

Geographical distribution: Out of a total of 164 isolates, 103 were S. boydii, 14 were S. dysenteriae, and 47 were non-serotypeable Shigella isolates. The highest number of $S$. boydii isolates was recovered in 2004 and 2006, the largest number being 42/103 (41\%). Shigella dysenteriae only appeared in seven of the 22 years surveilled. The highest number of $S$. dysenteriae isolates (6) was recovered in 2018 from Arauca (3), Bogotá (2), and Norte de Santander (figure 4). Shigella dysenteriae was not related to outbreaks.

Age: S. boydii was recovered mostly in under 14 -year-olds $(71 \%)$ while $S$. $d y s e n t e r i a e$ was recovered mostly from the $\geq 15$-year-old population. Nonserotypeable isolates were recovered in patients of all ages (table 3 ).

Antimicrobial resistance: S. boydii exhibited resistance to all evaluated antibiotics except ciprofloxacin. More than $75 \%$ of $S$. boydii isolates were resistant to ampicillin and tetracycline and half of these were resistant to trimethoprim-sulfamethoxazole.

Shigella dysenteriae was resistant to five of the ten evaluated antibiotics with a lower resistance rate than other species. However, the highest percentage of resistance to nalidixic acid was found in S. dysenteriae when compared with other evaluated species (11.1\%).

Non-serotypeable isolates showed resistance to seven of the evaluated antibiotics; characteristically, this group had the greatest resistance rate to ciprofloxacin (2.1\%) (table 2).

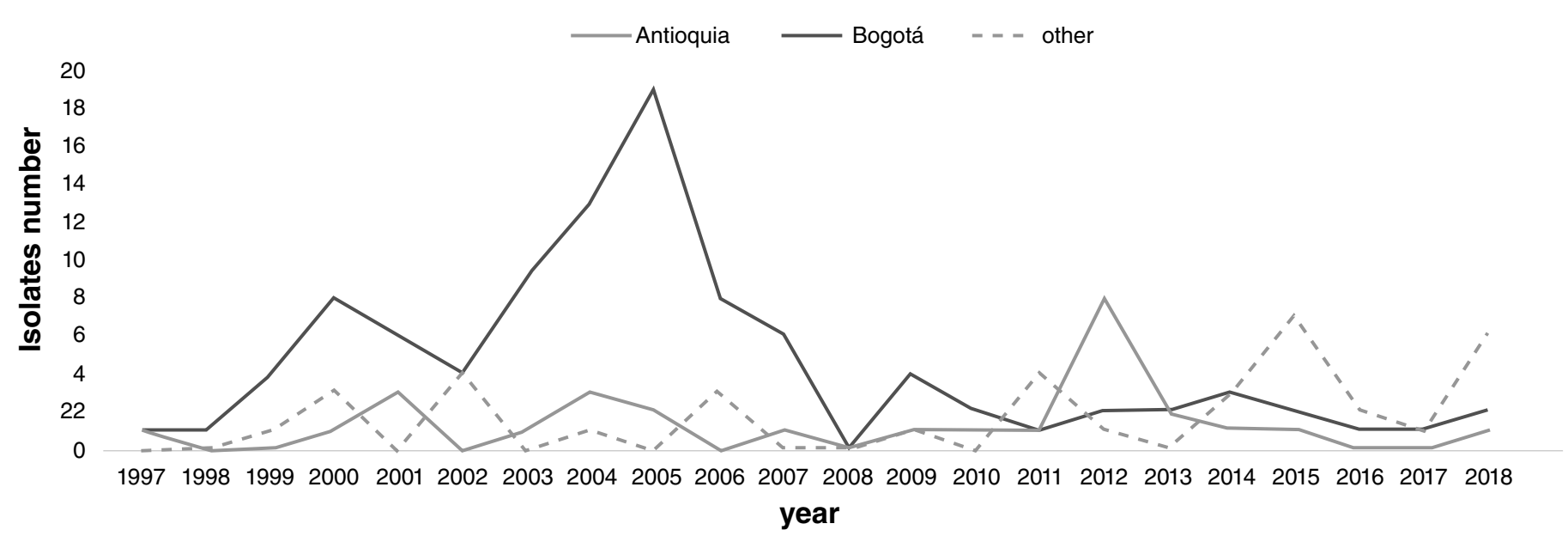

Figure 4. Comparison of the number and distribution of Shigella species different to sonnei and flexneri in Antioquia (black), Bogotá (grey), and other regions (dashed line) in Colombia from 1997 to 2018 


\section{Antimicrobial resistance evaluated per year and species}

\section{Beta-lactam antibiotics}

Amoxicillin/clavulanic acid: S. sonnei resistance began to appear in 2006 when $24.6 \%$ of the isolates were resistant; eleven years later, in 2017 , this resistance rate reached its highest level of almost $66 \%(p<0.05)$. In 2018 the resistance level significantly decreased (11.6\%; $p<0.05)$ (Table 4).

During the first five years of surveillance of $S$. flexneri, no resistance was recorded. Nonetheless, between 2002 and 2005, rates ranged from 22\% to $40.9 \%$; a year later, in 2006, they had increased significantly to $71.3 \%(p<0.05)$, and then they were stable until 2018 when there was a significant decrease to $35.2 \%(p<0.05)$. This was also observed in S. sonnei isolates. In the other species, resistance was detected in nine of the 22 years under surveillance and the highest resistance level was detected in 2017 (50\%) (Table 4).

Ampicillin: Since surveillance started in 1997 and for 12 years, the resistance in S. sonnei has remained above 50\%. In 2010, resistance rates increased significantly to $71.5 \%(p<0.05)$ and were stable until 2018 when they decreased significantly to $25.9 \%(p<0.05)$. In contrast, $S$. flexneri resistance rates to ampicillin remained high in the same period of time ranging from $62.7 \%$ to $92.8 \%$ (table 4 ). There were no resistant isolates from other species only in 2008, 2015, and 2017 (table 4).

Cefotaxime and ceftazidime: Resistance to cefotaxime was found in 21 isolates: 12 S. sonnei, 8 S. flexneri, and 1 S. boydii isolate while we detected 16 resistant isolates to ceftazidime: 10 S. sonnei, 4 S. flexneri, and 2 S. boydii isolates.

Table 4. Antimicrobial resistant isolates distribution per year in different Shigella species

\begin{tabular}{|c|c|c|c|c|c|c|c|c|c|c|c|c|c|c|c|c|c|c|c|c|c|c|c|}
\hline \multirow{2}{*}{$\begin{array}{l}\text { Shigella } \\
\text { species }\end{array}$} & & \multicolumn{22}{|c|}{ Year/antibiotic/resistance percentage } \\
\hline & & 97 & 98 & 99 & 00 & 01 & 02 & 03 & 04 & 05 & 06 & 07 & 08 & 09 & 10 & 11 & 12 & 13 & 4 & 5 & 6 & 7 & 8 \\
\hline IIEI & 714 & 100 & 95.0 & 85.7 & 5.2 & .9 & 6.3 & 97.4 & 90.8 & .3 & 2.4 & 92.0 & 93.7 & 782.8 & 85.6 & 81.6 & 86.3 & 70.0 & 70.2 & 70.3 & 54.2 & 2.5 & 41 \\
\hline & 2 & 100.0 & 100.0 & 60.0 & 100.0 & 77.8 & 100.0 & 90.0 & 94.1 & 71.4 & 100.0 & 100.0 & .0 & 33.3 & 66.7 & 66.7 & 54.5 & 75.0 & 57.1 & 50.0 & 66.7 & .0 & 3 \\
\hline \multicolumn{24}{|c|}{ Nalidixic acid } \\
\hline onnei & 574 & 0.0 & 0.0 & 0.0 & 0.0 & 0.0 & 0.6 & 1.3 & 1.1 & 2.4 & 2 & 7 & 2.1 & 14.0 & 3.0 & 7.0 & 12.8 & 18.6 & 9.4 & 14.1 & 6.3 & 38.1 & 25. \\
\hline & & 0.0 & 0.0 & 0.0 & 0.0 & 0.0 & 0.0 & 0.0 & 5.9 & 0.0 & & 0 & 0.0 & 0.0 & 66.7 & 73.3 & 39.1 & 0.0 & 16.7 & 10.0 & 0.0 & .0 & 0 \\
\hline \multicolumn{24}{|c|}{ Amoxicillin/clavulanic acid } \\
\hline 1 & 391 & 0.0 & 0.0 & 0.0 & 0.0 & 0.0 & 3.2 & 5.9 & 3.4 & 4 & 0 & 7.0 & 38.0 & 3.3 & 53 & 40.4 & 57.3 & 43.2 & 64.7 & 43.8 & 49.0 & 5.9 & 11. \\
\hline & & 0 & 0 & 0.0 & 0.0 & 0.0 & 3.4 & 37.8 & 2 & & & 66.7 & $\varepsilon$ & 4 & 47 & 74.3 & 35.7 & 78.8 & 1.7 & 76.0 & 62.5 & 5.5 & 35 \\
\hline & 30 & 0.0 & 0.0 & 0.0 & 0.0 & 0.0 & 0.0 & 11.1 & م & 9.5 & 27.3 & 28.6 & 0.0 & 0.0 & 33.3 & 30.0 & 9.1 & 0.0 & 28.6 & 22.2 & 0.0 & 50.0 & 0 \\
\hline \multicolumn{24}{|c|}{ Ampicillin } \\
\hline \multicolumn{24}{|c|}{ Trimethoprim-sulfamethoxazole } \\
\hline & & 94.4 & 0 & 76.2 & 1.6 & 89.7 & 0 & 9 & 87.4 & & & 3 & .0 & 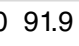 & 8 & 75.9 & 79.0 & 92.2 & 94.2 & 96.9 & 4.3 & 7.3 & 86. \\
\hline flexneri & 2,166 & 82.8 & 73.6 & 85.4 & 3.0 & 3.1 & 80.2 & 84.9 & 78.6 & 78.3 & & 71.4 & 69.1 & 66.7 & 56.8 & 58.8 & 30.0 & 57.4 & 56.4 & 88.0 & 1.9 & 48.5 & 48 \\
\hline 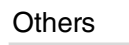 & 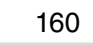 & 50.0 & 0.0 & 40.0 & 66.7 & 66.7 & 25.0 & 50.0 & 47.1 & 66.7 & 81.8 & 71.4 & .0 & 16.7 & 0.0 & 50.0 & 45.5 & 75.0 & 40.0 & 62.5 & 6.7 & 100.0 & 44. \\
\hline \multicolumn{24}{|c|}{ Chloramphenicol } \\
\hline & $2,1 \cup 0$ & 11.1 & 5.0 & 0.0 & 1.2 & 2.6 & 0.6 & 9.2 & 13.7 & 11.9 & 16.8 & 11.4 & 30.3 & 320.2 & 42.5 & 37.7 & 60.3 & 51.4 & 59.9 & 54.3 & 53.8 & 50.0 & 21. \\
\hline Fexneri & 2,149 & 69.0 & 88.7 & 75.0 & 64.8 & 83.1 & 74.5 & 584.0 & 75.6 & 78.1 & 87.4 & 85.5 & 87.7 & 785.7 & 86.3 & 83.6 & 85.4 & 83.1 & 85.0 & 75.0 & 75.9 & 74.2 & 76. \\
\hline thers & 164 & 50.0 & 0.0 & 20.0 & 0.0 & 11.1 & 0.0 & 20.0 & 5.9 & 14.3 & 18.2 & 14.3 & 30.0 & 0.0 & 0.0 & 16.7 & $7 \quad 9.1$ & 25.0 & 57.1 & 40.0 & 33.3 & 0.0 & 11. \\
\hline
\end{tabular}


Tetracycline: From the very first year of S. sonnei surveillance, we found resistance levels in more than $90 \%$ of the isolates which decreased to $70 \%$ as of 2013 reaching the lowest levels in 2018 with $41.2 \%$. Shigella flexneri isolates showed more than $90 \%$ resistance during 17 of the surveillance years registering the lowest rates (83.3\%) in 2018. Resistance rates in other species fluctuated: in some years there were no resistant isolates (2008 and 2017) while resistance levels reached $100 \%$ in $1997,1998,2000,2002,2006$, and 2007 (Table 4).

Trimethoprim-sulfamethoxazole: In S. sonnei, resistance remained constant during the study period ranging from $75.9 \%$ to a maximum of $96.6 \%$ in 2006 and 2015, respectively. In S. flexneri resistance levels exceeded $65 \%$ until 2010 and then decreased to $48.8 \%$ in 2018 . Regarding other species, resistance rates varied more: in 1998, 2008, and 2010 , isolates were completely sensitive while in 2017 resistance rates reached 100\% (table 4).

Quinolones and fluoroquinolones: Resistance to nalidixic acid in S. sonnei was higher than in other species remaining stable (below 10\%) until 2012 with a maximum level in 2017 (38.1\%). In 2016 alone, S. flexneri resistant isolates exceeded $20 \%$ while in other years this level did not exceed $6 \%$ (table 4 ). Ciprofloxacin-resistant isolates amounted to only 24 : S. sonnei (14), S. flexneri (9), and S. boydii (1).

Phenicols: The highest resistance rate was detected in S. flexneri with more than $70 \%$ of isolates during surveillance years. In S. sonnei isolates, resistance rates were less than $30 \%$ until 2008, when they began to increase until reaching $60.3 \%$ in 2012 . For other species, resistance levels varied during the surveillance years (table 4).

Aminoglycosides: Gentamicin was evaluated within the aminoglycoside class and we detected 12 resistant isolates: seven were S. sonnei, four $S$. flexneri, and one S. boydii.

\section{Resistance profiles}

The most frequent resistance profile was detected in 1,001/5,043 (19.8\%) isolates and it corresponded to multidrug resistance (resistance to three or more antibiotic classes: (TE-C-AMC-AMP-SXT) (Table 5). Resistance rates were similar in S. flexneri and S. sonnei (Table 5).

Other resistance profiles were specific for each species. The most frequent in S. flexneri were TE-C-AMP (91.6\%), TE-C-SXT (87.7\%), TE-C-AMC-AMP (83.5\%), and TE-C-AMP-SXT (77.5\%). Interestingly, the main S. sonnei resistance profile was to SXT solely $(92 \% ; 277 / 301)$ followed by resistance to two antibiotics: TE-SXT (86\%; 825/959). Furthermore, compared with S. flexneri, fewer multidrug-resistant isolates from other species were detected. TE-AMC-AMP-SXT: 78.2\%; AMP-SXT: $77.9 \%$, and TE-AMP-SXT: $75.6 \%$ were the most frequent resistance profiles (table 5).

\section{Discussion}

Diarrheal diseases continue to cause morbidity and mortality in low- and middle-income countries. Estimates from 195 countries reveal that global diarrhea mortality among individuals older than 5 years has been dominated by Shigella spp. (13). Additionally, Shigella spp. was the leading cause of diarrheal mortality among people older than 70 years $(14,15)$. 
Table 5. Antimicrobial resistance profiles distribution in different Shigella species

\begin{tabular}{lrccccc}
\hline \multicolumn{7}{c}{ Shigella species } \\
\hline Resistance profiles & $\begin{array}{c}\text { flexneri } \\
\mathbf{n}(\%)\end{array}$ & $\begin{array}{c}\text { sonnei } \\
\mathbf{n}(\%)\end{array}$ & $\begin{array}{c}\text { boydii } \\
\mathbf{n}(\%)\end{array}$ & $\begin{array}{c}\text { dysenteriae } \\
\mathbf{n}(\%)\end{array}$ & $\begin{array}{c}\text { Shigella spp. } \\
\mathbf{n}(\%)\end{array}$ & $\begin{array}{c}\mathbf{n} \\
\text { isolates }\end{array}$ \\
\hline TE-C-AMC-AMP-SXT & $555(55.4)$ & $442(44.2)$ & $3(0.3)$ & 0 & $1(0.1)$ & 1,001 \\
TE-SXT & $125(13)$ & $825(86)$ & $4(0.4)$ & $1(0.1)$ & $4(0.4)$ & 959 \\
TE-AMP-SXT & $90(16.9)$ & $402(75.6)$ & $33(6.2)$ & $2(0.4)$ & $5(0.9)$ & 532 \\
TE-C-AMP-SXT & $410(77.5)$ & $109(20.6)$ & $3(0.6)$ & $1(0.2)$ & $6(1.1)$ & 529 \\
TE-C-AMC-AMP & $374(83.5)$ & $73(16.3)$ & 0 & 0 & $1(0.2)$ & 448 \\
SXT & $16(5.3)$ & $277(92)$ & $3(1)$ & 0 & $5(1.7)$ & 301 \\
AMP-SXT & $27(17.5)$ & $120(77.9)$ & $2(1.3)$ & $1(0.6)$ & $4(2.6)$ & 154 \\
TE-C-AMP & $141(91.6)$ & $8(5.2)$ & $4(2.6)$ & 0 & $1(0.6)$ & 154 \\
TE-C-SXT & $128(87.7)$ & $17(11.6)$ & 0 & 0 & $1(0.7)$ & 146 \\
TE-AMC-AMP-SXT & $30(21.1)$ & $111(78.2)$ & $1(0.7)$ & 0 & 0 & 142 \\
Other profiles (n=78) & $245(36.2)$ & $377(55.7)$ & $40(5.9)$ & $1(0.8)$ & $14(2.1)$ & 677 \\
\hline Total & 2,141 & 2,761 & 93 & 6 & 42 & 5,043 \\
\hline
\end{tabular}

AMC: Amoxicillin/clavulanic acid; TE: Tetracycline; C: Chloramphenicol; NA: Nalidixic acid; CAZ: Ceftazidime; CTX: Cefotaxime; AMP: Ampicillin; SXT: Trimethoprim sulfamethoxasole; CIP: Ciprofloxacin; GM: Gentamicin

In this report, most of the strains were isolated from under 6-yearold children. Shigella sonnei resistance profile included trimethoprimsulfamethoxazole_solely, which indicates that age could be an important factor in acquiring Shigella infection in Colombia. The findings we present were supported by a prospective surveillance study also performed in Colombia to determine the incidence of Shigella spp. in acute gastroenteritis that revealed that $23 \%$ of the isolates were associated with hospitalization and outpatient care in single infections and coinfections among children between 24 and 59 months of age (16). As described in the Global Enteric Multicenter Study (GEMS), Shigella spp. burden increased proportionally with age and became the second most common pathogen identified among 12 to 23 months children and the leading pathogen among 24 to 59 months ones (17).

The dominant species was $S$. flexneri in the first three years (1997 to 1999 ) and in the last three years of surveillance (2016 to 2018). Since 2000 and for 16 years (2000 to 2015), the dominant species was S. sonnei in all the departments under study. This 'replacement phenomenon' has been documented in many countries in different regions of the world such as Asia and it supports the emergence of $S$. sonnei replacing $S$. flexneri as the most frequent agent of shigellosis in economically transitional states $(18,19)$.

Shigella sonnei and S. flexneri were the most common isolates coinciding with reports at global level. For example, reports on the incidence of several Shigella species in countries of the Americas evidenced their presence in an urban community in Ecuador and in a Chilean periurban area $(20,21)$. Additionally, the current global epidemiological burden for shigellosis is attributed to these two species: $S$. flexneri, conventionally associated with lowand middle-income countries, and S. sonnei with high-income regions (19) .

Noticeably, regions that had undergone significant industrialization reported increasing cases of $S$. sonnei compared to low- and middle-income areas where $S$. flexneri levels have remained high (22). It has been suggested that this shifting trend may be due to an improvement of overall nutritional status (23), socioeconomic level, and sanitation conditions (24). It has also been suggested that such shift is mediated by cross-immunity. In lessdeveloped countries, repeated ingestion of Plesiomonas shigelloides bacteria through consumption of untreated surface waters may stimulate crossprotection against $S$. sonnei with $\mathrm{O}$ antibodies mediating protection (25). 
The appearance of $S$. flexneri in our study as the most common species during the last three years of surveillance could be an indicator of a decline in the quality of water supply and good sanitation in Colombian communities. It has been shown that an increase in the provision of clean water and sanitation possibly disrupts $S$. flexneri traditional transmission route (26).

Regarding the other species evaluated in our report, $S$. boydii and $S$. dysenteriae, we observed fewer isolates, which agrees with other worldwide reports $(10,17,27)$, but outbreaks of both species have been reported $(28,29)$.

We recovered $S$. dysenteriae isolates sporadically, one or two strains during the 23 years of surveillance. However, in 2018 , six isolates were recovered from three different departments, two of them located in borders (Arauca and Norte de Santander); isolates of these species had not been previously reported in these states. According to previous reports, their presence may indicate the possibility of an epidemic in these or other regions within Colombia (30).

These isolates were evaluated for the presence of Shiga toxin and were negative. Some did not react with any Shigella serogroup/serotype-specific antisera. Other studies have found similar results with strains classified as untypable by serotyping in many other countries (31-33).

Regarding the antimicrobial resistance profiles of species under study, we found the highest resistance levels to tetracycline, trimethoprimsulfamethoxazole, and ampicillin, a trend also observed in Africa, Asia, and other South American countries where ampicillin resistance rates were high for almost all Shigella species. In most of the studies in Africa and Asia, Shigella serogroups developed resistance to tetracycline, chloramphenicol, and trimethoprim-sulfamethoxazole (34-36).

Additionally, resistance levels to amoxicillin/clavulanic acid reached almost $50 \%$ in our study, which was higher than the Latin American mean reported by the Antimicrobial Surveillance Program where $27 \%$ of the isolates were resistant to this antibiotic but less frequent than the $71 \%$ reported in Europe (35).

Resistance rates to cefotaxime, ceftazidime, gentamicin, and ciprofloxacin were less than $1 \%$. In general, the antimicrobial resistance level for these antibiotics is similar across Latin America where ceftriaxone is active against all Shigella spp. and fluoroquinolone-resistant isolates are limited $(35,37)$.

The antimicrobial resistance against specific species revealed that $S$. sonnei had the highest resistance level to trimethoprim-sulfamethoxazole. Indeed, S. sonnei resistant isolates were found in all surveillance years. The resistance to amoxicillin/clavulanic acid reached its highest rate in 2017 and abruptly decreased by more than $50 \%$ during 2018 , which was unexpected considering the behavior of the isolates reported herein.

Only $6 \%$ of $S$. flexneri isolates were susceptible to tetracycline, which means that more than $90 \%$ of the population is resistant. Likewise, ampicillin and chloramphenicol resistance were higher in S. flexneri isolates than in all other evaluated species. A similar situation has been revealed in other parts of the world with high rates of resistance to at least one of the common antibiotics such as ampicillin, tetracycline, and chloramphenicol $(38,39)$.

Contrary to reports of $S$. flexneri resistance to gentamicin, nalidixic acid, and ciprofloxacin (34) in other regions, our resistant isolates did not reach high resistance levels. A similar situation occurred for cephalosporin where resistance was less than $1 \%$, similar to that reported by Lima, et al. (40). 
The S. boydii isolate we analyzed here exhibited resistance to all antibiotics evaluated except for ciprofloxacin. Interestingly, this species had the highest resistance rates to cephalosporin and gentamicin. Regarding tetracycline, ampicillin, and trimethoprim-sulfamethoxazole, the trend was similar to previous reports (34).

We found the highest percentage of resistance to nalidixic acid in $S$. dysenteriae isolates, similar to those in India and Bangladesh where an alarming $82 \%$ resistance in this species was reported $(41,42)$. In Egypt, Wasfy, et al., found over $50 \%$ resistance levels to chloramphenicol, tetracycline, and ampicillin $(43,44)$. However, compared to other studies $(31,45)$, in ours the isolates had lower levels of resistance to other antibiotics evaluated and were completely sensitive to amoxicillin/clavulanic acid, ceftazidime, cefotaxime, and ciprofloxacin.

An increase in fluoroquinolone resistance in S. flexneri and S. sonnei isolates in high-income countries has been reported and, although nalidixic acid resistance was common among $S$. sonnei isolates, the trend of fluoroquinolone resistance is slowly increasing $(46,47)$. Oral ciprofloxacin can achieve high concentrations in serum and stool and has activity against Shigella isolates. However, ciprofloxacin should not be prescribed for children (48).

In Colombia, quinolones are not generally recommended for shigellosis treatment, which may have contributed to the low levels of resistance observed. Macrolide azithromycin is widely used in children and is recommended as an alternative therapy for the treatment of shigellosis in adults infected with multidrug-resistant isolates (49); however, in vitro azithromycin susceptibility testing is not routinely performed by the country's Shigella surveillance system.

Our laboratory-based surveillance of Shigella spp. determined that children under five years of age were affected by all of them. These findings should be considered by funders and public health officials to make evidence-based decisions for effective protection and prevention including attainable vaccines. Characteristically, an increased frequency of multidrug resistant S. flexneri was observed. Following international epidemiological trends, S. sonnei is likely to become more prevalent on a global scale as countries increase their level of development and sanitation. Combating the spread of global antibiotic resistance will be greatly benefited by focusing on S. sonnei surveillance while more localized efforts are needed to combat $S$. flexneri resistance.

\section{Acknowledgments}

The authors wish to thank Carolina Duarte Valderrama for her management surveillance activities in the Laboratorio de Microbiología at the Instituto Nacional de Salud.

\section{References}

1. GBD Diarrhoeal Diseases Collaborators. Estimates of global, regional, and national morbidity, mortality, and aetiologies of diarrhoeal diseases: A systematic analysis for the Global Burden of Disease Study 2015. Lancet Infect Dis. 2017;17:909-48. https://doi.org/10.1016/S1473-3099(17)30276

2. Bardhan P, Faruque ASG, Naheed A, Sack DA. Decrease in shigellosis-related deaths without Shigella spp.-specific interventions, Asia. Emerg Infect Dis. 2010; 1:1718-23. https://doi.org/ 10.3201/eid1611.090934

3. Mattock E, Blocker AJ. How do the virulence factors of Shigella work together to cause disease? Front Cell Infect Microbiol. 2017;7:64. https://doi.org/10.3389/fcimb.2017.00064 
4. Liu J, Platts-Mills JA, Juma J, Kabir F, Nkeze J, Okoi C, et al. Use of quantitative molecular diagnostic methods to identify causes of diarrhoea in children: A reanalysis of the GEMS case-control study. Lancet. 2016;388:1291-301. https://doi.org/ 10.1016/S0140-6736(16)31529-X.

5. Muthuirulandi Sethuvel DP, Devanga Ragupathi NK, Anandan S, Veeraraghavan B. Update on: Shigella new serogroups/serotypes and their antimicrobial resistance. Lett Appl Microbiol. 2017;1:8-18. https://doi.org/10.1111/lam.12690

6. DuPont HL, Levine MM, Hornick RB, Formal SB. Inoculum size in shigellosis and implications for expected mode of transmission. J Infect Dis. 1989;159:1126. https://doi.org/10.1093/infdis/159.6.1126

7. World Health Organization. Guidelines for the control of shigellosis, including epidemics due to Shigella dysenteriae type 1. Accessed: May 21, 2019. Available from: https://www.who.int/cholera/publications/shigellosis/en/

8. Anderson M, Sansonetti PJ, Marteyn BS. Shigella diversity and changing landscape: Insights for the twenty-first century. Front Cell Infect Microbiol. 2016;6:45. https://doi.org/10.3389/fcimb.2016.00045

9. Chang Z, Lu S, Chen L, Jin Q, Yang J. Causative species and serotypes of shigellosis in mainland China: Systematic review and meta-analysis. PLOS ONE. 2012;7:52515. https://doi.org/10.1371/journal.pone.0052515

10. Baker S, The HC. Recent insights into Shigella. Curr Opin Infect Dis. 2018;31:449-54. https://doi.org/10.1097/QC0.0000000000000475

11. Ewing WH. Edwards and Ewing's identification of Enterobacteriaceae. $4^{\text {th }}$. edition. New York Elsevier Science Publishing Co., Inc.; 1986. p. 536.

12. Clinical and Laboratory Standards Institute. Clinical and Laboratory Standards Institute. Performance standards for antimicrobial susceptibility testing; Twenty-third informational supplement. Wayne: CLSI; 2017.

13. Troeger C, Blacker BF, Khalil IA, Rao PC, Cao S, Zimsen SR, et al. Estimates of the global, regional, and national morbidity, mortality, and aetiologies of diarrhoea in 195 countries: A systematic analysis for the Global Burden of Disease Study 2016. Lancet Infect Dis. 2018;18:1211-28. https://doi.org/10.1016/S1473-3099(18)30310-4

14. Platts-Mills JA, Babji S, Bodhidatta L, Gratz J, Haque R, Havt A, et al. Pathogen-specific burdens of community diarrhoea in developing countries: A multisite birth cohort study (MALED). Lancet Glob Health. 2015;18:1191-210. https://doi.org/10.1016/S2214-109X(15)00151-5

15. López EL, Prado-Jiménez V, O’Ryan-Gallardo M, Contrini MM. Shigella and shiga toxinproducing Escherichia coli causing bloody diarrhea in Latin America. Infect Dis Clin North Am. 2000;14:41-65. https://doi.org/ 10.1016/S0891-5520(05)70217-8

16. López-Medina E, Parra B, Dávalos DM, López P, Villamarín E, Peláez M. Acute gastroenteritis in a pediatric population from Cali, Colombia in the post rotavirus vaccine era. Int J Infect Dis. 2018;73: 52-9. https://doi.org/10.1016/j.ijid.2018.06.006

17. Kotloff KL, Nataro JP, Blackwelder WC, Nasrin D, Farag TH, Panchalingam S, et al. Burden and aetiology of diarrhoeal disease in infants and young children in developing countries (the Global Enteric Multicenter Study, GEMS): A prospective, case-control study. Lancet. 2013;382:209-22. https://doi.org/10.1016/S0140-6736(13)60844-2

18. Vinh H, Nhu NTK, Nga TVT, Duy PT, Campbell Jl, Hoang NVM, et al. A changing picture of shigellosis in southern Vietnam: Shifting species dominance, antimicrobial susceptibility and clinical presentation. BMC Infect Dis. 2009;9:204. https://doi.org/10.1186/1471-2334-9-204

19. Thompson CN, Duy PT, Baker S. The rising dominance of Shigella sonnei: An intercontinental shift in the etiology of bacillary dysentery. PLoS Negl Trop Dis. 2015;9:e0003708. https://doi.org/10.1371/journal.pntd.0003708

20. Vasco G, Trueba G, Atherton R, Calvopiña M, Cevallos W, Andrade T, et al. Identifying etiological agents causing diarrhea in low income Ecuadorian communities. Am J Trop Med Hyg. 2014; 91:563-9. https://doi.org/10.4269/ajtmh.13-0744

21. Ferreccio C, Prado V, Ojeda A, Cayyazo M, Abrego P, Guers L, et al. Epidemiologic patterns of acute diarrhea and endemic Shigella infections in children in a poor periurban setting in Santiago, Chile. Am J Epidemiol. 1991;6:614-27. https://doi.org/10.1093/oxfordjournals.aje.a116134 
22. Qiu S, Xu X, Yang C, Wang J, Liang B, Li P, et al. Shift in serotype distribution of Shigella species in China, 2003-2013. Clin Microbiol Infect. 2015;21:252. https://doi.org/10.1016/j.cmi.2014.10.019

23. Faruque ASG, Ahmed AMS, Ahmed T, Islam MM, Hossain MI, Roy SK, et al. Nutrition: Basis for healthy children and mothers in Bangladesh. J Health Popul Nutr.2008;26:325-39. https://doi.org/10.3329/jhpn.v26i3.1899

24. Fewtrell L, Kaufmann RB, Kay D, Enanoria W, Haller L, Colford JM Jr. Water, sanitation, and hygiene interventions to reduce diarrhoea in less developed countries: A systematic review and meta-analysis. Lancet Infect Dis. 2005;5:42-52. https://doi.org/10.1016/S1473-3099(04)01253-8

25. Sayeed S, Sack DA, Qadri F. Protection from Shigella sonnei infection by immunisation of rabbits with Plesiomonas shigelloides (SVC O1). J Med Microbiol. 1992;6:382-4. https://doi.org/10.1099/00222615-37-6-382

26. Esrey SA, Feachem RG, Hughes JM. Interventions for the control of diarrhoeal diseases among young children: Improving water supplies and excreta disposal facilities. Bull World Health Organ. 1985;63:757-72.

27. Ram PK, Crump JA, Gupta SK, Miller MA, Mintz ED. Part II. Analysis of data gaps pertaining to Shigella infections in low and medium human development index countries, 1984-2005. Epidemiol Infect. 2008;136:577-603. https://doi.org/10.1017/S0950268807009351

28. Löfdahl M, Ivarsson S, Andersson S, Långmark J, Plym-Forshell L. An outbreak of Shigella dysenteriae in Sweden, May-June 2009, with sugar snaps as the suspected source. Eurosurveillance. 2009;14:19268. https://doi.org/10.2807/ese.14.28.19268-en

29. Smith AM, Keddy KH, Sooka A, Ismail H, DeJong GM. Analysis of a temporal cluster of Shigella boydii isolates in Mpumalanga, South Africa, November to December 2007. J Infect Dev Ctries. 2009;3:65-70. https://doi.org/10.3855/jidc. 107

30. Ud-Din AIMS, Wahid SUH, Latif HA, Shahnaij M, Akter M, Azmi IJ, et al. Changing trends in the prevalence of Shigella species: Emergence of multi-drug resistant Shigella sonnei biotype $\mathrm{g}$ in Bangladesh. PLOS ONE. 2013;8:e82601. https://doi.org/10.1371/journal.pone.0082601

31. Zafar A, Hasan R, Nizami SQ, von Seidlein L, Soofi S, Ahsan T, et al. Frequency of isolation of various subtypes and antimicrobial resistance of Shigella from urban slums of Karachi, Pakistan. Int J Infect Dis. 2009;6:668-72. https://doi.org/110.1016/j.ijid.2008.10.005

32. Isenbarger DW, Hien BT, Ha HT, Ha TT, Bodhidatta L, Pang LW, et al. Prospective study of the incidence of diarrhoea and prevalence of bacterial pathogens in a cohort of Vietnamese children along the Red River. Epidemiol Infect. 2001;2:229-36. https://doi.org/10.1017/s0950268801005933

33. Roy S, Thanasekaran K, Dutta Roy AR, Sehgal SC. Distribution of Shigella enterotoxin genes and secreted autotransporter toxin gene among diverse species and serotypes of Shigella isolated from Andaman Islands, India. Trop Med Int Health. 2006;11:1694-8. https://doi.org/10.1111/j.1365-3156.2006.01723.x

34. Kahsay AG, Muthupandian S. A review on sero diversity and antimicrobial resistance patterns of Shigella species in Africa, Asia and South America, 2001-2014. BMC Res Notes. 2016;9:422. https://doi.org/ 10.1186/s13104-016-2236-7

35. Streit JM, Jones RN, Toleman MA, Stratchounski LS, Fritsche TR. Prevalence and antimicrobial susceptibility patterns among gastroenteritis-causing pathogens recovered in Europe and Latin America and Salmonella isolates recovered from bloodstream infections in North America and Latin America: Report from the SENTRY Antimicrobial Surveillance Program (2003). Int J Antimicrob Agents. 2006;27:367-75. https://doi.org/10.1016/j.ijantimicag.2005.12.004

36. Penatti MPA, Hollanda LM, Nakazato G, Campos TA, Lancellotti M, Angellini M, et al. Epidemiological characterization of resistance and PCR typing of Shigella flexneri and Shigella sonnei strains isolated from bacillary dysentery cases in Southeast Brazil. Braz J Med Biol Res. 2007;40:249-58. https://doi.org/10.1590/S0100-879X2006005000069

37. Seribelli AAp, Frazão MR, Medeiros MIC, Falcão JP. Molecular and phenotypic characterization of strains of Shigella sonnei isolated over 31 years suggests the circulation of two prevalent subtypes in São Paulo State, Brazil. J Med Microbiol. 2016;65:666-77. https://doi.org/10.1099/jmm.0.000290

38. Khaghani S, Shamsizadeh A, Nikfar R, Hesami A. Shigella flexneri: A three-year antimicrobial resistance monitoring of isolates in a Children Hospital, Ahvaz, Iran. Iran J Microbiol. 2014;6:225-9. 
39. Cui X, Wang J, Yang C, Liang B, Ma Q, Yi S, et al. Prevalence and antimicrobial resistance of Shigella flexneri serotype 2 variant in China. Front Microbiol. 2015;6:435.

https://doi.org/10.3389/fmicb.2015.00435

40. Lima AA, Sidrim JJ, Lima NL, Titlow W, Evans ME, Greenberg RN. Molecular epidemiology of multiply antibiotic-resistant Shigella flexneri in Fortaleza, Brazil. J Clin Microbiol. 1997;35:1061-5. https://doi.org/10.1128/JCM.35.5.1061-1065.1997

41. Khatun F, Faruque A, Koeck JL, Olliaro P, Millet P, Paria N, et al. Changing species distribution and antimicrobial susceptibility pattern of Shigella over a 29-year period (19802008). Epidemiol Infect. 2011;139:446-52. https://doi.org/10.1017/S0950268810001093

42. Taneja N. Changing epidemiology of shigellosis and emergence of ciprofloxacin-resistant Shigellae in India. J Clin Microbiol. 2007;45:678-9. https://doi.org/10.1128/JCM.02247-06

43. Wasfy MO, Oyofo BA, David JC, Ismail TF, el-Gendy AM, Mohran ZS, et al. Isolation and antibiotic susceptibility of Salmonella, Shigella, and Campylobacter from acute enteric infections in Egypt. J Health Popul Nutr. 2000;18:33-8.

44. El-Gendy A, Mansour A, Weiner M, Pimentel G, Armstrong A, Young S, et al. Genetic diversity and antibiotic resistance in Shigella dysenteriae and Shigella boydii strains isolated from children aged <5 years in Egypt. Epidemiol Infect. 2012;140:299-310. https://doi.org/10.1017/S0950268811000525

45. von Seidlein L, Kim DR, Ali M, Lee H, Wang X, Thiem VD, et al. A multicentre study of Shigella diarrhoea in six Asian countries: Disease burden, clinical manifestations, and microbiology. PLoS Med. 2006;3:353. https://doi.org/10.1371/journal.pmed.0030353

46. Vrints M, Mairiaux E, van Meervenne E, Collard J-M, Bertrand S. Surveillance of antibiotic susceptibility patterns among Shigella sonnei strains isolated in Belgium during the 18-year period 1990 to 2007. J Clin Microbiol. 2009;47:1379-85. https://doi.org/10.1128/JCM.02460-08

47. Kim J-Y, Kim S-H, Jeon S-M, Park M-S, Rhie H-G, Lee B-K. Resistance to fluoroquinolones by the combination of target site mutations and enhanced expression of genes for efflux pumps in Shigella flexneri and Shigella sonnei strains isolated in Korea. Clin Microbiol Infect. 2008;14:760-5. https://doi.org/10.1111/j.1469-0691.2008.02033.x

48. Jain SK, Gupta A, Glanz B, Dick J, Siberry GK. Antimicrobial-resistant Shigella sonnei: Limited antimicrobial treatment options for children and challenges of interpreting in vitro azithromycin susceptibility. Pediatr Infect Dis J. 2005;24:494-7. https://doi.org/ 10.1097/01.inf.0000164707.13624.a7

49. Boumghar-Bourtchai L, Mariani-Kurkdjian P, Bingen E, Filliol I, Dhalluin A, Ifrane SA, et al Macrolide-resistant Shigella sonnei. Emerg Infect Dis. 2008;14:1297-9. https://doi.org/10.3201/eid1408.080147 